\title{
3D analysis of the soil porous architecture under \\ long term contrasting management systems by X-ray \\ Computed Tomography
}

\author{
L.F. Pires ${ }^{a}$, W.L. Roque ${ }^{b}$, J.A. Rosa ${ }^{c}$, S.J. Mooney ${ }^{d}$ \\ a Laboratory of Physics Applied to Soils and Environment, Department of Physics, State University of Ponta Grossa, \\ 84.030-900, Ponta Grossa, PR, Brazil \\ ${ }^{b}$ Petroleum Engineering Modelling Laboratory, Department of Scientific Computation, Federal University of Paraíba, \\ 58.051-900, João Pessoa, PB, Brazil \\ c Laboratory of Soil Physics, Agricultural Research Institute of Paraná, 84.001-970, Ponta Grossa, PR, Brazil \\ ${ }^{\mathrm{d}}$ Division of Agricultural and Environmental Sciences, School of Biosciences, University of Nottingham, Sutton \\ Bonington Campus, Leicestershire LE12 5RD, UK
}

Corresponding author:

Prof. Dr. Luiz F. Pires, Phone: (55) 423220 3044. Fax: (55) 42-3220-3042

E-mail: Ifpires@uepg.br (Luiz F. Pires);

Proofs should be sent to:

Prof. Luiz Fernando Pires, Departamento de Física, Universidade Estadual de Ponta Grossa, Campus de Uvaranas, Bloco L, Sala 15B; Av. Carlos Cavalcanti, 4748, CEP 84.030-900, Ponta Grossa, PR, Brazil. 


\title{
3D analysis of the soil porous architecture under long
} term contrasting management systems by X-ray Computed Tomography

\author{
L.F. Pires ${ }^{a, 1}$, W.L. Roque ${ }^{b}$, J.A. Rosa ${ }^{c}$, S.J. Mooney ${ }^{d}$ \\ a Laboratory of Physics Applied to Soils and Environment, Department of Physics, State \\ University of Ponta Grossa, 84.030-900, Ponta Grossa, PR, Brazil \\ ${ }^{b}$ Petroleum Engineering Modelling Laboratory, Department of Scientific Computation, Federal \\ University of Paraíba, 58.051-900, João Pessoa, PB, Brazil \\ ${ }^{c}$ Agricultural Research Institute of Paraná, 84.001-970, Ponta Grossa, PR, Brazil \\ ${ }^{a}$ Division of Agricultural and Environmental Sciences, School of Biosciences, University of \\ Nottingham, Sutton Bonington Campus, Leicestershire LE12 5RD, UK
}

\section{ABSTRACT}

The development of adequate soil structure is important for achieving good physical status, which influences the sustainability of agricultural areas. Different management systems lead to the development of a wide range of soil pore network characteristics. The objective of this research was to analyze the effect of three contrasting tillage systems (zero-tillage, ZT; reduced tillage, RT; conventional tillage, CT) in the soil porous system of an Oxisol. Samples were collected from the surface layer $(0-10 \mathrm{~cm})$. An area under secondary forest (F) was also assessed to provide an undisturbed reference. X-ray Computed Tomography $(\mu \mathrm{CT})$ scanning of undisturbed soil samples and image analysis were employed for analysis of the pore network. The soil under ZT

\footnotetext{
1 Corresponding author Tel.: +55 42 3220-3044

E-mail addresses: luizfpires@gmail.com; Ifpires@uepg.br (L.F. Pires)
} 
had the smallest porosity in comparison to the other management systems. The conventionally tilled soil had the largest porosity and the most connected pores. One large connected pore was responsible for around $90 \%$ of the porosity of the resolvable pores $(>35 \mu \mathrm{m})$ studied for all the management systems. Pores of elongated shapes, which enhance water movement through the soil, were the most frequent pores in terms of shape.

Keywords: Minimum tillage; Zero-tillage; Conventional tillage; Morphological properties; X-ray microtomography; Soil structure.

\section{INTRODUCTION}

The use of tillage has been employed for centuries to improve soil structure for enhanced crop development. However, the choice of tillage systems can have a significant impact on a soil heath and quality. Sustainable farming systems greatly depend on soil quality (Bünemann et al., 2018). Soil tillage provokes substantial changes in several soil physical properties such as total porosity, bulk density, water retention and infiltration, penetration resistance, pore size distribution, connectivity and tortuosity (Imhoff et al., 2010; Daraghmeh et al., 2009; Blanco-Canqui et al., 2004; Katsvairo et al., 2002).

In Brazil the adoption of minimum tillage systems such as reduced (RT) and zero tillage $(\mathrm{ZT})$ is common. The total Brazilian area used in crop production is around 66 million hectares and there are over 31 million hectares under ZT (FEBRAPDP, 2013). Conventional tillage (CT) is characterized by the disruption of the top soil due to ploughing and harrowing operations employed to turn over and loosen the soil. As a result of these operations, macropores are created and pore continuity is disrupted, which directly affect the water movement (e.g. hydraulic conductivity and infiltration) and retention (Blanco-Canqui et al., 2017; Ogunwole et al., 2015; Cássaro et al., 2011; Imhoff et al., 2010). Minimum tillage systems such as RT and ZT do not usually lead to 
drastic soil structure changes. These systems, known as conservation techniques, have been utilized as a means of reducing tillage and field costs as well as for conserving soil structure due to reduced disturbance (Aziz et al., 2013; Cavalieri et al., 2009). The residues of the previous crop are left intact and the absence of harrowing in $\mathrm{ZT}$ and RT can increase soil organic carbon and aggregate stability, reduce $\mathrm{CO}_{2}$ emissions and moderate fluxes of water, air and heat through the soil (Aziz et al., 2013; Daraghmeh et al., 2009; Zibilske and Bradford, 2007).

The fluxes of water and air, organic matter decomposition, plant-available water and soil resistance to erosion are directly linked to the architecture of the soil porous system. Mesopores and macropores play an important role in these processes (Imhoff et al., 2010; Fuentes et al., 2004; Cameira et al., 2003). In CT, the soil porous system is affected by operations such as ploughing and harrowing, which can increase porosity and loosen soil (Mangalassery et al., 2014). This operation allows good root growth and air exchange, while the exposition of the soil to rain in tropical regions can sometimes lead to erosion (Alvarez et al., 2009). On the other hand, the activity of earthworms and root decay help to create channels and burrows under RT and ZT, which facilitate drainage and gaseous diffusion (Soto-Gómez et al., 2018; Carducci et al., 2017; Pires et al., 2017; Pierret et al., 2002).

Based on the important functions that mesopores and macropores fulfill for a healthy soil, techniques to image and measure key properties such as X-ray Computed Tomography $(\mu \mathrm{CT})$ are very important (Tseng et al., 2018; Yang et al., 2018; Ferreira et al., 2018; Pagenkemper et al., 2014). The spatial distribution of pores can be nondestructively imaged at high resolutions and in three dimensions (3D) by $\mu \mathrm{CT}$ (e.g. Galdos et al. 2018; Helliwell et al., 2013; Peth et al., 2008). $\mu$ CT has been previously applied with success to study the size, shape, number, connectivity, degree of anisotropy, macropore thickness, fractal dimension and tortuosity of the soil porous system (Wang et al., 2016; Dal Ferro et al., 2014; Garbout et al., 2013; Vogel, 1997). 
This provides vital information to characterize the physical structure of the porous system, which allows a better understanding of key processes (i.e. mass and energy transport, nutrient cycling, root development) within the soil (Hillel, 2004).

Previous studies on evaluating the influence of tillage systems at the $\mu \mathrm{m}$ scale in 3D in tropical soils are still scarce. In Brazil, one of the largest food and agricultural producers of the world, previous studies have characterized the soil porous system at $\mu \mathrm{m}$ to measure the porosity and pore size distribution of Brazilian Oxisols (Vaz et al., 2011), assessed the effect of tillage systems on the percentage of macropores (Beraldo et al., 2014) and explored the spatial and morphological configuration of the pore space of Oxisols under CT (Carducci et al., 2017, 2014). Other studies have determined the influence of $\mathrm{ZT}$ on the pore size and shape distribution of macropores (Passoni et al., 2015), tested the capacity of soil recovering under different management strategies (Marchini et al., 2015) and measured the impact of ZT and CT on the pore size and shape distribution and water retention (Pires et al., 2017). Recent work has analyzed the soil structure utilizing the geometrical parameters of the soil porous system (Tseng et al., 2018), considered the influence of liming on the structure of aggregates under ZT (Ferreira et al., 2018) and revealed the structural development associated with long term (>30 years) ZT (Galdos et al., 2018).

The objective of this particular research was to apply the X-ray Computed Tomography technique to evaluate, in $3 \mathrm{D}$ and at the $\mu \mathrm{m}$ scale, the morphological properties of an Oxisol under contrasting soil management systems. Experimental areas under long term zero-tillage and reduced and conventional tillage systems were investigated. Samples were collected at the soil surface layer $(0-10 \mathrm{~cm})$.

\section{MATERIALS AND METHODS}

The experimental field plots of this study were located in Ponta Grossa, in a humid mesothermal Cfb-subtropical region in southern Brazil $\left(25^{\circ} 09^{\prime} \mathrm{S}, 50^{\circ} 09^{\prime} \mathrm{W}, 875 \mathrm{~m}\right.$ 
above sea level) (Cássaro et al., 2011). The soil was an Oxisol (Rhodic Hapludox) with clay texture according to USDA soil taxonomy (Soil Survey Staff, 2013). The experimental areas have long gentle slopes ranging from 2 to $7 \%$. The Oxisol evolved from the clastic sediments of the Devonian period characterized by a mixture of Ponta Grossa shale (MINEROPAR, 2013). Deep and very structured profiles are found in the experimental site characterized by high porosities and good internal drainage (Sá et al., 2015).

Three tillage systems were compared in this study (conventional tillage - CT, reduced tillage $-\mathrm{RT}$ and zero-tillage $-\mathrm{ZT})$. An area under secondary forest $(\mathrm{F})$ was utilized as baseline to assess the management-induced changes in soil structure, which is located close to $(\approx 200 \mathrm{~m}$ far $)$ the experimental field plots. Some of the key characteristics of the soil $(0-10 \mathrm{~cm}$ depth) from the experimental areas are shown in Table 1.

The experimental plots studied here have areas of c. 1.0 ha (ZT) and c. 0.6 ha (CT and RT), respectively. The tillage systems had been employed in the areas for over 35 years at the time of sampling. The experimental areas of CT, RT and ZT were initiated in 1981 after conversion of part of secondary forest to pasture-land (Sá et al., 2015). Under CT, the soil was submitted to discing at $25 \mathrm{~cm}$ depth followed by $10 \mathrm{~cm}$ harrowing twice a year after summer and winter harvest. For the area under RT, the soil was prepared through the use of a chisel cultivator at $25 \mathrm{~cm}$ depth followed by a 10 cm narrow disking, causing minimum soil disturbance, and the crop residues were maintained at the soil surface. The area under ZT was not submitted to soil disturbance. In these areas, crop rotation was performed, with cover crops [oats (Avena strigosa) or vetch (Vicia sativa)] or wheat (Triticum aestivum L.) in winter and corn (Zea mays) or soybean (Glycine max) in summer (Table 2). The operations of soil and crop management, sowing and harvest, were made with commercial tillage machines (e.g. tractor). The traffic in the $\mathrm{ZT}$ area was restricted to sowing equipment 
with a cutting disc for sowing the summer and winter crops. Each experimental area

130 (ZT, CT and RT) was submitted to 8-9 soil interventions through the year (clearing, planting seed and soil preparation operations) using tractors around four tonnes in weight.

Soil samples were taken from the 0-10 cm layer after corn harvest in April 2017.

134 For CT, sampling occurred almost six months after ploughing and harrowing operations, which allowed the sampling of natural reconsolidated structures. ZT, RT and $\mathrm{F}$ samples were also taken at the same sampling time. Core samples of $91 \mathrm{~cm}^{3}$ (5.0 cm high and $4.8 \mathrm{~cm}$ inner diameter) were collected in steel cylinders with an Uhland core sampler (Folegatti et al., 2001). Three samples of each tillage system and forest ( 3 samples $\times 4$ systems) were collected for the macroporosity and microporosity analyses and other five samples ( 5 samples $\times 4$ systems) for the $\mu \mathrm{CT}$ analysis (Table 1). After sampling, the samples were wrapped in plastic foil and transported to the laboratory. The soil excess outside the steel cylinders was carefully trimmed off and top and bottom surfaces of the sample were made flat to ensure that the soil volume was equal to the internal volume of the cylinder. This procedure was carried out with the help of a palette knife.

Samples were collected very carefully, in order not to introduce soil compaction during extraction and handling of the steel cylinders. To minimize damages in the soil structure due to the force required for collection, samples were taken some days after a high intensity rainfall event with the soil near its plastic limit. For organic carbon (3 samples $\times 4$ systems) and texture (3 samples $\times 4$ systems) measurements, disturbed soil samples were collected at three different points. Soil organic carbon was determined by the Walkley-Black method and texture by the hydrometer method (Gee and Or, 2002; Nelson and Sommers, 1982).

The soil samples were carefully extracted from the steel cylinders before the $\mu \mathrm{CT}$ scans. Prior to the scanning, the samples were coated with paraffin wax for 
transport to the United Kingdom. Each soil sample was scanned using a GE v|tome|x m

157 X-ray $\mu \mathrm{CT}$ scanner (GE Measurement \& Control Solutions, Wunstorf, Germany) at the 158 Hounsfield Facility (The University of Nottingham, Sutton Bonington Campus, U.K.). 159 The voltage, current and integration time adopted for the image acquisition process were $180 \mathrm{kV}, 160 \mu \mathrm{A}$ and $250 \mathrm{~ms}$. A $0.1 \mathrm{~mm}$ Cu-filter was used to minimize beamhardening effects. A total of 2520 projections were obtained per sample with a pixel resolution of $35 \mu \mathrm{m}$. Therefore, it was not possible to quantify pores below the resolution mentioned.

The radiographs of each scan were reconstructed in 32 bit format in order to avoid compression of the greyscale histogram. After reconstruction the images were imported into Volumetric Graphics (VG) StudioMAX® 2.0 and cropped (i.e. resized) to a cubic shape with $30.1 \times 30.1 \times 30.1 \mathrm{~mm}^{3}(860 \times 860 \times 860$ pixels $)$. The image cropping was carried c. $10 \mathrm{~mm}$ away from the borders of the samples to avoid possible artifacts on the edge of the soil core samples that may have arisen from sampling or transport.

The original grey-level $\mu \mathrm{CT}$ images were processed using ImageJ 1.42 software (Rasband, 2007). A 3D median filter with radius of 2 voxels was applied to reduce noise in the images. Subsequently, an unsharp mask with standard deviation of 1 voxel and weight of 0.8 was applied to emphasize edges. The segmentation process was based on the nonparametric and unsupervised Otsu method of thresholding (Otsu, 1979). The remove outlier tool with radius of 0.75 was applied in the images after segmentation. The images were also visually inspected to verify the quality of the segmentation procedure. This resulted in a binary image, in which pores and solids were respectively represented by white and black pixels.

For the 3D structure analysis, soil pores were classified according to their shape and size distribution. For the shape classification, parameters known as major, intermediate and minor axes of the ellipsoids that represent each pore were 
determined by using 3D measuring techniques (Borges et al., 2018; Pires et al., 2017). These parameters were measured by using the Particle Analyser tool in the ImageJ. The soil pores were classified according to Zingg (1935) based on the relations of the intermediate by the major (Int./Maj.) and of the minor by the intermediate (Min./Int.) axes. Equant (EQ), Prolate (PR), Oblate $(\mathrm{OB})$ and Triaxial $(\mathrm{TR})$ shaped pores were analyzed (Ferreira et al., 2018; Pires et al., 2017) (Table 3). When one of the axes of a specific pore could not be determined, this pore was not classified (unclassified pore) according to its shape. These pores are generally associated with enhanced complexity of individual pores, which means that a geometrical shape cannot be fitted for them.

3D porosity was determined for all pores $>8$ voxels and the total number of pore voxels within the region of interest. Isolated pores smaller than 9 voxels were removed from the porous fraction of the images in the quantitative analyses to avoid misclassification from unresolved voxels (Jefferies et al., 2014). The total number of isolated pores within the region of interest was utilized for the 3D pore size distribution based on the volume of pores $\left(0.0004-0.01,0.01-0.1,0.1-10\right.$ and $\left.>10 \mathrm{~mm}^{3}\right)$ (Ferreira et al., 2018; Pires et al., 2017).

The network tortuosity and connectivity of the pores were calculated using Osteoimage software (Roque et al., 2009). Tortuosity was determined through the geodesic reconstruction algorithm implemented by Roque et al. (2012). The pore network degree of connectivity was estimated by the Euler-Poincare Characteristic (EPC). EPC is a topological property of geometric objects and one of the Minkowski functions used for describing the connectivity of spatial structures (Katuwal et al., 2015). This parameter for a $3 D$ structure is related to the number of isolated parts minus the connectivity of an object (Thurston, 1997). To estimate the EPC, a stack of serial sections called dissectors (Sterio, 1984) is used. In our study 859 disectors were analyzed for each sample. EPC by the volume of dissectors (EPC $)$ was then 
210 calculated for each sample after the images had been previously submitted to the

211 Purify procedure in Bone $\mathrm{J}$ plugin (Toriwaki and Yonekura, 2002; Odgaard and 212 Gundersen, 1993). For $\mathrm{EPC}_{v}$ a positive value indicates a poorly connected structure 213 while a negative value suggests a more connected structure (Vogel and Kretzschmar, 214 1996). The Euler number was also utilized to evaluate the connectivity of the main pore network (i.e. the largest pore). The degree of anisotropy, which gives the preferred orientation of pores, was determined in 3D by using the BoneJ plugin (Doube et al., 2010).

Differences in the soil morphological parameters due to the treatments were evaluated by a one-way analysis of variance (ANOVA) followed by Tukey's HSD post hoc tests. Results were classified as statistically significant at $p<0.05$. Parameters such as the mean, standard deviation and coefficient of variations were also measured for each soil physical property analyzed. Pearson correlations among each pair of variables were measured for some of the morphological properties. The statistical analysis was carried out using PAST software (Hammer et al., 2001).

\section{RESULTS AND DISCUSSION}

Representative 3D images of the soil porous system from the different management systems are presented in Fig. 1. The undisturbed samples collected at the surface layer for the contrasting tillage systems possessed a main pore network composed of connected pores. The 3D images show that the soil under CT seemed to have a high proportion of small connected pores in relation to F, ZT and RT (Fig. 1). The numerous pores observed for the soil under CT suggest this management system was characterized by higher soil porosity than the other treatments. Larger soil pores were observed for the soil under F, ZT and RT, which may be an indication of biological activity. The existence of biopores in areas under forest or conservation management systems is usually associated with the action of earthworms and root penetration (Peth et al., 2008). Normally these biopores tend to be vertically oriented, continuous and 
237 round shaped (Pagenkemper et al., 2015). Earthworm activity in the soil modifies its 238 structure and can affect the transport and exchange processes such as preferential 239 flows and lateral water movement (Rogasik et al., 2014). other management systems (Fig. 2a). Porosity was c. 2.3 times higher for CT than ZT. 242 Significant differences $(p<0.05)$ were observed for $\mathrm{ZT}$ in relation to the other management systems. The number of pores was significantly different between $\mathrm{CT}, \mathrm{F}$ and ZT (Fig. 2b). The soil under ZT had the highest number of pores followed by F, RT and CT. The number of disconnected pores was c. 1.5 times higher for ZT than CT.

The lowest porosity observed for ZT maybe associated with a "zero-tillage pan", which can happen in areas under long term ZT as previously observed in the South of Brazil down to $20 \mathrm{~cm}$ soil depth (Mazurana et al., 2017; da Silva et al., 2009; Klein and Libardi, 2002). According to Reichert et al. (2007), soil compaction in ZT can occur mainly when this practice is utilized for long periods due to machinery traffic, low soil mobilization and natural soil arrangement. One of the consequences of this densification is the reduction of macroporosity and the increase in microporosity (da Silva et al., 2016; Mangalassery et al., 2014). Similar findings for areas under ZT close to the experimental plots studied were observed by Borges et al. (2018) and Pires et al. (2017) for samples collected in different periods of time. Normally, for soils under ZT it is expected that the traffic effects can be compensated by the creation of macropores originating from the fauna activity, high organic content and root development, but this was not observed in this study. Similar results were recorded by Blanco-Canqui et al. (2017) and Soracco et al. (2012).

The large porosity observed under CT is probably associated with the soil loosening and disturbance, which favours the formation of macropores at the surface layer (Jabro et al., 2009). Conventional management can cause an increase in the volume of pores, permeability and air flow, which is related to the harrowing and 
264 ploughing operations (Rossetti et al., 2013). For the soil under RT, the porosity can be explained by reduced soil disturbance combined with the incorporation of residues from previous crops for this management (Cunha et al., 2015). In terms of porosity, this management presents the most similar results to the reference area $(F)$.

The smallest number of pores was for the soil under CT, which was unexpected (Fig. 2b). The aggregate breakdown induced by harrowing and ploughing operations normally increases the number of pores due to the loosening effect of conventional management systems. Several previous studies have demonstrated that systems with ploughing are characterized by looser soil structures (Dal Ferro et al., 2014; Garbout et al., 2013; Munkholm et al., 2012; Munkholm and Hansen, 2012). Borges et al. (2018) and Pires et al. (2017) also observed a larger number of pores for the soil under CT than ZT for the same experimental area. A possible explanation for the smaller number of pores observed under CT in the current study could be the soil resettling, which is induced by the local wetting and drying cycles, caused by rainfall and dry periods and biological activity including root growth (Daraghmeh et al., 2009).

The contrasting management systems did not demonstrate significant differences in the degree of anisotropy though it was highest in RT, followed by ZT and CT, whereas F had the smallest value (Fig. 2c). This parameter was c. 1.7 times higher for RT than F. The results of degree of anisotropy obtained in this study are in line with those presented by Dal Ferro et al. (2014). These authors obtained values of 0.21 (CT) and $0.25(Z T)$ for samples from the topsoil $(0-10 \mathrm{~cm})$. However, there was no pattern between the results of degree of anisotropy and porosity among the different management approaches. Strong linear positive and negative correlations were observed for RT ( $r=0.63)$, and $\mathrm{ZT}(r=-0.60)$ and $F(r=-0.86)$ between these two parameters, which shows that the soil under ZT presented similarities with F. The smallest degree of anisotropy obtained for $\mathrm{F}$ indicates a more isotropic porous system, which means that pores are not oriented in particular directions and there are 
291 similarities in the pore orientation in the different directions analyzed (Hernández

292 Zubeldia et al., 2016). Therefore, this kind of porous system does not present a 293 tendency for preferential flows but is expected that the water can infiltrate and also 294 redistribute into the soil in all directions in similar conditions as per Darcy's Law. Tseng et al. (2018) also observed small values for the degree of anisotropy for a native forest area in comparison to degraded or recovering pasture land. The degree of anisotropy data indicated that all management systems had a good physical condition as far as water infiltration is concerned. For comparison, Tseng et al. (2018) observed values of 0.64 for an area of degraded soil and Garbout et al. (2013) of 0.37 for a direct drilling management system.

The pore connectivity measured by the volumetric Euler-Poincaré Characteristic was lowest for CT followed by RT, F and ZT (Fig. 2d). Significant differences $(p<0.05)$ of this parameter were observed only between $\mathrm{CT}$ and ZT. For these two management systems the increase in pore connectivity was also followed by the increase in the degree of anisotropy (strong linear positive correlations: $r=0.74$ for CT and $r=0.60$ for ZT) of the soil porous system, which indicates slight differences in the spatial characteristics of the pores in some specific direction in the images (Tseng et al., 2018). The same tendency of the volumetric Euler-Poincaré Characteristic was found for the pore connectivity (Euler number) of the largest pore $(C T<R T<F<Z T)$, which was c. 2.8 times smaller for CT than ZT (Fig. 2e). Surprisingly, the highest pore connectivity was observed for the soil under CT. We expected that the breakdown of aggregates should decrease the pore connectivity due to soil loosening as observed by Dal Ferro et al. (2014). However, as the samples were collected months after ploughing and harrowing operations, the reorganization of the soil particles and aggregates, as

315 function of the corn root system and weather conditions, may favour the connectivity of 316 the pores under CT (Strudley et al., 2008). Muñoz-Ortega et al. (2015) observed that 
317 soils under tilled areas can present structures similar to natural conditions, which can lead to highly connected porous systems.

From a visual inspection of the 3D images (Fig. 1), we observed that all the management systems presented a main, highly connected pore network. The results of the volumetric Euler-Poincaré Characteristic and Euler number indicate that the soils with the largest porosity had the best pore connectivity, which can be associated with the junction of few large pores with many tunnels or a high amount of small connected pores (Vogel, 1997). Although, there was no clear relation between overall porosity and soil pore connectivity (results not shown), which indicates that probably other physical properties have a greater influence on the pore connectivity than the porosity. In the case of $\mathrm{ZT}$ and $\mathrm{RT}$, it was expected that the pore connectivity was mainly associated with the biological activity, root decay and low or nonexistent soil disturbance (Aziz et al., 2013; Daraghmeh et al., 2009; Zibilske and Bradford, 2007). Continuous pores can be produced by crack formation, earthworm activity or retention of crop residues maintained after harvesting on the soil surface, which act as physical barriers making the soil less susceptible to erosion or the pressure of agricultural machine traffic under crop residue harvest (Imhoff et al., 2010). In the case of RT, the soil cutting induced by chiseling preserves cracks and channels between aggregates, which creates interconnected pores with large volumes (Peña-Sancho et al., 2017). Despite low porosity observed for ZT, pore connectivity was positively influenced by the organic matter content at the soil surface, which may have compensated the negative influence of macroporosity reduction (Franzluebbers et al., 2011). Martins et al. (2011), working at the same experimental area of our study, found differences of around $42 \%$ in the carbon content at the topsoil between CT and ZT after 27 years of management.

The results obtained here for porosity and pore connectivity are extremely valuable due to the importance of the mesopores and macropores for water infiltration and retention. Changes in the soil porous system induced by tillage can present 
significant modifications in the hydraulic properties of the soil as pointed out by Alvarez et al. (2009), Daraghmeh et al. (2008) and Buczko et al. (2006). The importance of soil structure to conserve the quality and the health of the soil, reduce net $\mathrm{CO}_{2}$ emissions, and increase organic carbon pools is another vital aspect for the micrometric characterization of this porous system; conventional and conservational management systems play an important role in all of these processes (Zibilske and Bradford, 2007).

The soil pore system tortuosity was calculated for different directions $(x, y, z)$, and an average tortuosity was obtained considering the three directions together (Fig. 3). The calculation of tortuosity for different directions is related to the influence of this parameter for the movement of water and air through the soil. This movement occurs in all directions across the soil, and changes in the soil porous system in one direction certainly have the possibility of inducing preferential flows in the soil profile. Significant differences $(p<0.05)$ in the average $\tau$ was observed between CT and F, and ZT (Fig. 3a). The lowest average tortuosity was measured for ZT, followed by RT, CT and F. Porosity and average tortuosity were strongly correlated only for $F(r=0.78)$ and $Z T$ $(r=0.77)$, which indicates an increase in pore complexity with an increase in porosity for these two cases. The presence of crop residues in decomposition in ZT and soil fauna in F can help to explain these results (Franzluebbers et al., 2011).

The tortuosity in the $\mathrm{x}$ - and $\mathrm{y}$-directions was the highest in F, followed by CT and RT, then ZT (Figs. 3b,c). Significant differences were found only between $F$ and ZT for both tortuosity directions. Porosity and $\mathrm{x}$ - and $\mathrm{y}$-direction tortuosities were strongly correlated for all the management systems $(r=0.86$ for $\mathrm{CT} ; \mathrm{r}=0.93$ for $\mathrm{RT} ; \mathrm{r}=0.88$ for $\mathrm{ZT}$ - -direction tortuosity and $\mathrm{r}=0.87$ for $\mathrm{CT}$; $\mathrm{r}=0.78$ for $\mathrm{RT}$; $\mathrm{r}=0.93$ for $\mathrm{ZT}-\mathrm{y}$-direction tortuosity) and $F(r=0.90-x$-direction tortuosity and $r=0.83-y$-direction tortuosity). In general, the results of $x$ - and $y$-direction and average tortuosities had the same tendency among management systems. The tortuosity in the z-direction was not characterized by significant differences between F, CT and RT, whereas ZT was 
371 different from F (Fig. 3d). The highest z-direction tortuosity was observed for F,

372 followed by RT, CT and ZT. The average tortuosity as well as that in the $x-, y-$ and z-

373 directions was c. 1.1 times higher for F than ZT. Porosity was strongly correlated to z-

374 direction tortuosity only for $F(r=0.86)$ and weakly correlated for CT $(r=0.17)$, which was

375 probably associated with the soil loosening and disturbance in the last case (Munkholm

376 et al., 2012; Munkholm and Hansen, 2012).

The lowest average tortuosity was in the ZT soil indicating that pores are more aligned for this management. The same results were found for the tortuosity in the different directions. Usually, more aligned pores can sometimes be associated with a better interconnected network of more continuous flow channels (Peth et al., 2008). However, the better alignment of the pores for ZT did not result in a better pore connectivity as observed by the weak linear negative correlation between average tortuosity and volumetric Euler-Poincaré Characteristic $(r=-0.22)$. This means that the more aligned and continuous pores possibly were not interconnected with other pore networks. Tortuosity is mainly related to the degree of complexity of the sinuous porous path (Pagenkemper et al., 2014; Rezanezhad et al., 2010). Despite the better connectivity measured for CT compared to the other management systems, this connectivity is probably associated with the junction of small pores as observed in the 3D images (Muñoz-Ortega et al., 2015; Vogel, 1997). Therefore, the highest tortuosity observed for $\mathrm{CT}$ in comparison to $\mathrm{ZT}$ is possibly related to a higher number of connected small pores. Similar findings were found by Borges et al. (2018) and Peth et al. (2008). The highest tortuosity was measured for the soil under F, which can be associated with the complexity of the soil porous system due to biological activity, soil fauna (insects), roots, a greater amount of residues (tree leaves) maintained at the soil surface and the absence of tillage (Blanco-Canqui and Lal, 2007). soil structure associated with soil depth. The more aligned pores in this direction can 
be associated with wider and more continuous flow channels, which can improve the water infiltration in this direction. The effective transport of fluids through the pore networks is not only dependent on their continuity but also on their tortuosity (Peth et al., 2008). The similarities in the values of tortuosity for the different directions indicate that the pore complexity follows a similar pattern in all directions analyzed. However, average tortuosity was strongly negatively correlated to the degree of anisotropy for CT $(r=-0.90), Z T(r=-0.72)$ and $F(r=-0.66)$, which means that the presence of more tortuous pores does not necessarily affect the distribution of pores.

In general, the tortuosity data described well aligned pores for all the 407 management systems studied. This result is important because the tortuosity is associated with the hydraulic conductivity. This parameter indicates increased resistance to flow, which means high tortuosity can negatively affect the capacity of soil to water transport (Rezanezhad et al., 2010).

The pore morphology characterized by the shape of pores is similar to the other parameters studied in that it directly affects the movement of water, air and the development of roots through the soil. Changes in the shape of pores due to management will influence the water retention and the amount of water available to plants. The highest contribution of equant (e.g. equant spheroid) shaped pores to the total porosity was observed for F, followed by RT, CT and ZT (Fig. 4a). The proportion of equant shaped pores was c. 1.3 times higher for F than ZT. Significant differences $(p<0.05)$ were identified between F, ZT and CT. For prolate (e.g. prolate spheroid / rod) shaped pores (Fig. 4b), the highest contribution to porosity was found for RT, followed by $\mathrm{F}, \mathrm{ZT}$ and $\mathrm{CT}$. The proportion of prolate shaped pores was $\mathrm{c} .1 .1$ times higher for

421 RT than CT. No significant differences were recorded between management systems 422 for this type of pore shape. The highest contribution of oblate (e.g. oblate spheroid / 423 discoid) shaped pores to porosity was measured for F, followed by CT, RT and ZT (Fig. 4c). The proportion of oblate shaped pores was c. 1.3 times higher for CT than ZT. 
425 Similar to the results of prolate shaped pores, no significant differences were observed

426 between the different management systems. The highest contribution to porosity was

427 verified for pores of triaxial (e.g. blade) shape (Fig. 4d). The following sequence among

428 management systems was found for triaxial shaped pores: $\mathrm{F}<\mathrm{RT}<\mathrm{CT}<\mathrm{ZT}$; and the

429 proportion of them was c.1.1 times higher for ZT than F. Significant differences were 430 observed between F, ZT and CT.

The presence of slightly to very flat/elongated (e.g. prolate, oblate and triaxial)

432

433

434

pores was greatly influenced by different soil management systems. The presence of earthworms and insects, mainly at the soil surface, will contribute to the appearance of elongated pores (Jarvis et al., 2017; Pagenkemper et al., 2015; Rogasik et al., 2014). According to Pagliai et al. (2004), elongated continuous pores affect plant growth by easing root penetration and increasing the transmission and storage of water and gases. The smallest proportion of platy and equant shaped pores is an indication of a good soil structure (Pagliai et al., 2004; Bouma et al., 1977). The largest proportion of slightly to moderately flat/elongated pores is indicative of soil quality, since they are generally related to the biological activity of living organisms and roots (biopores) (Carducci et al., 2014; Lima et al., 2005). The Euler number showed moderate $(r=0.52$ for $\mathrm{ZT}$ ) to strong ( $\mathrm{r}=0.76$ for $\mathrm{CT}$ and $\mathrm{r}=0.84$ for $\mathrm{RT}$ ) positive correlations in relation to the contribution of triaxial shaped pores to porosity, which means that the largest presence of these type of pores can positively contribute to water infiltration. However, samples of $F$ had only weak correlation $(r=0.17)$ between these two morphological properties, which can be associated with the increased complexity of the porous system. We observed that the average tortuosity was strongly correlated $(r=0.67)$ to the triaxial shaped pores contribution to the porosity for F. In conventional management, the presence of elongated pores is usually associated with planar shaped pores surrounding or separating aggregates or clods (Pagliai, 1994). The recovery of soil structure, which occurs in soils managed under conventional management systems 
452 after months of ploughing and harrowing operation procedures, can also be identified

453 by an increase in the proportion of elongated pores (Zhao et al., 2017). The largest amount of equant shaped pores in $\mathrm{F}$ can also be related to the biologic activity. This pore type also plays an important role in the transport and retention of water, since water can infiltrate very quickly in tubular pores (Yang et al., 2018). A strong positive correlation ( $r=0.61)$ was found between the volumetric Euler-Poincaré Characteristic and the contribution of equant shaped pores to porosity for $F$, which highlights the importance of this type of pore in native or secondary forests.

A large portion of the pores were not classified in terms of shape. The contribution of unclassified pores to porosity was around $60 \%$ for $\mathrm{F}$ and $\mathrm{RT}, 66 \%$ for $\mathrm{ZT}$ and $63 \%$ for CT, respectively. Moderate to strong positive correlations were found between the volumetric Euler-Poincaré Characteristic and the contribution of unclassified pores for all the management systems ( $r=0.58$ for ZT, $r=0.91$ for CT and $r=0.85$ for $R T)$ and $F(r=0.56)$. As unclassified pores were responsible for a considerable part of the porosity, their contribution to pore connectivity is important and suggests the samples analyzed are characterized by good structural quality. Unclassified pores are also an indicative of the complexity of the soil porous system. The well connected pore structures observed in the 3D images give an idea of the complexity of the soil porous system (Fig. 1). Similar results of a high contribution of complex pores to the overall porosity have also been previously measured for Brazilian soils (Ferreira et al., 2018; Borges et al., 2018; Costa et al., 2018; Pires et al., 2017; Passoni et al., 2015).

The small pores (from 0.0004 to $10 \mathrm{~mm}^{3}$ ) made only a small contribution to overall porosity. The highest contribution to porosity for 0.0004 to $0.01 \mathrm{~mm}^{3}$ pores was 476 observed in ZT, followed by F, RT and CT. Significant differences $(p<0.05)$ were 477 recorded between management systems for this pore size interval (Fig. 5a). Porosity displayed strong negative correlations to the interval of pore volumes between 0.0004 
and $0.01 \mathrm{~mm}^{3}$ for $\mathrm{F}(\mathrm{r}=-0.79)$, CT $(\mathrm{r}=-0.94)$ and $\mathrm{RT}(\mathrm{r}=-0.99)$. For the pore sizes of 0.01

480 to $0.1 \mathrm{~mm}^{3}$ (Fig. 5b), significant differences were observed between $\mathrm{ZT}$ and the other

481

482

483

484

485

486

487

488

489

490

491

492

493

494

495

496

497

498

499

500

501

502

503

504 management systems. Porosity also displayed strongly negative correlations to the interval of pore volumes between 0.01 and $0.1 \mathrm{~mm}^{3}$ for $F(r=-0.90)$, CT $(r=-0.92)$ and RT $(r=-0.89)$. For the last two size intervals of pores, the increase in porosity was followed by a decrease in the contribution of small pores, which highlights the great contribution of large pores to the overall soil porous system of F, CT and RT studied. The correlation between porosity and the two previous pore size intervals analyzed was moderate to weak for ZT ( $r=-0.41$ for 0.0004 to $0.01 \mathrm{~mm}^{3}$ and $\mathrm{r}=-0.29$ for 0.01 to $0.1 \mathrm{~mm}^{3}$ ). This result shows that the variation in porosity was not greatly influenced by changes in the distribution of small pore sizes for this management.

The highest contribution to porosity for 0.1 to $10 \mathrm{~mm}^{3}$ pores was observed for ZT, followed by F, RT and CT (Fig. 5c). Similar to the results observed for the 0.01 to $0.1 \mathrm{~mm}^{3}$, significant differences were found only between $\mathrm{ZT}$ and the other management systems. For the largest pores $\left(>10 \mathrm{~mm}^{3}\right)$, the greatest contribution to porosity occurred for CT, followed by RT, F and ZT. The soil under ZT presented significant differences in comparison to the other management systems (Fig. 5d). The proportion of different pore volume intervals to porosity was c. $3.5(0.0004$ to 0.01 $\left.\mathrm{mm}^{3}\right)$, c. $4.3\left(0.01\right.$ to $\left.0.1 \mathrm{~mm}^{3}\right)$ and c. $4.0\left(0.1\right.$ to $\left.10 \mathrm{~mm}^{3}\right)$ times higher for ZT than CT and c. 1.1 times higher for CT than ZT for the largest pore sizes $\left(>10 \mathrm{~mm}^{3}\right)$ studied.

We observed that in general the samples with high porosities were also characterized by a large contribution of the biggest pores $\left(>10 \mathrm{~mm}^{3}\right)$ to the porosity, which was corroborated by the strong positive correlations obtained for $F(r=0.82)$, CT $(r=0.93)$ and RT $(r=0.94)$ between these two soil physical properties. This is an indication of highly connected pore networks supported by the moderate to strong negative correlations between the volumetric Euler-Poincaré Characteristic and the 
505

contribution of pores $>10 \mathrm{~mm}^{3}$ to porosity for $\mathrm{ZT}(\mathrm{r}=-0.73)$, CT ( $\left.\mathrm{r}=-0.81\right)$ and RT ( $\mathrm{r}=-$ $0.50)$ of the soil samples analyzed.

In terms of pore size distribution, the contribution of pores $<10 \mathrm{~mm}^{3}$ to porosity was around $4 \%$ for $\mathrm{F}, 8 \%$ for $\mathrm{ZT}, 2 \%$ for $\mathrm{CT}$ and $3 \%$ for $\mathrm{RT}$. This indicates that a large part of the porosity is composed of large inter-aggregate pores as observed by Costa et al. (2018). Ferreira et al. (2018) recently showed that $>90 \%$ of porosity for a soil under ZT consisted of a main pore network as observed in our study. This type of pore system is related to soil structural development and it is indicative of structures that function well for water infiltration (Bullock and Thomasson, 1979). Borges et al. (2018) and Pires at al. (2017) obtained similar results for the same experimental area. Cássaro et al. (2011), in another work in the same site, identified a great concentration of large pores under ZT and CT management systems. The greatest contribution of unclassified pores to porosity is also indication of the presence of a main pore network composed by large pores (Costa et al., 2018; Jefferies et al., 2014). Garbout et al. (2013) determined that the volume of connected pores constituted $91 \%$ and $85 \%$ for drilling and ploughing areas, which indicates the great contribution of a main pore network to the overall porosity. Dal Ferro et al. (2014) also observed a contribution of around $70 \%$ of macropores to porosity, which would contribute to water infiltration and potentially reduce erosion (Imhoff et al., 2010).

\section{CONCLUSIONS}

We analyzed the structure of samples of an Oxisol under different management systems using X-ray Computed Tomography. The qualitative results obtained through $3 \mathrm{D}$ visual image analysis showed that the soils under all the management systems (zero-tillage, conventional tillage and reduced tillage) and forest are generally composed of a large main pore network which is highly connected. The pore connectivity results demonstrated that even for $\mathrm{ZT}$, which was characterized by a lower comparable mesoporosity and macroporosity, the soil porous system has a strongly 
connected pore network compared to the forest. We attribute this lower porosity for ZT to a possible development of a zero-tillage pan. However, the results of pore connectivity, degree of anisotropy and tortuosity show that the soil structure under ZT was not negatively affected by the reduction in its porosity. The smallest average tortuosity and the largest contribution of triaxial shaped pores found for ZT can help to explain the pore connectivity results. A moderate positive correlation was also measured between the volumetric Euler-Poincaré Characteristic and the unclassified pores for ZT similar to the results of F. As a great part of the porosity was comprised of unclassified pores for all the management systems and forest, these pores present an important contribution to the overall pore connectivity. The largest proportion of elongated shaped pores also demonstrated that all the management systems examined had positive effects in the quality of the soil porous system. Similar to the 3D image visualizations, the largest contribution to porosity was due to the presence of a main pore network, which means the porous system was well connected in all the management systems. The results of this study provided a detailed characterization of the soil porous system at the micrometric scale. This type of information is extremely important due to the relevance of mesopores and macropores in the transport of mass and energy through the soil. We can conclude that each of the management systems studied here presented positive indications of soil quality, which is surprising given their differences in operation and extremely important from an environmental and agricultural points of view.

\section{ACKNOWLEDGEMENTS}

LFP would like to acknowledge the financial support provided by the Brazilian National Council for Scientific and Technological Development (CNPq) and the Coordination for the Improvement of Higher Education Personnel (Capes) through the Grants 303726/2015-6 (Productivity in Research) and 88881.119578/2016-01 (Visiting 
558 Scholar). We acknowledge the helpful laboratory and computational work from Dr.

559 Brian Atkinson.

560 REFERENCES

561 Alvarez, C.R., Taboada, M.A., Gutierrez Boem, F.H., Bono, A., Fernandez, P.L., 562 Prystupa, P., 2009. Topsoil properties as affected by tillage systems in the rolling Pampa region of Argentina. Soil Sci. Soc. Am. J. 73, 1242-1250.

564

Aziz, I., Mahmood, T., Islam, K.R., 2013. Effect of long term no-till and conventional 565 tillage practices on soil quality. Soil Tillage Res. 131, 28-35.

566

Beraldo, J.M.G., Scannavino Junior, F.A., Cruvinel, P.E., 2014. Application of x-ray computed tomography in the evaluation of soil porosity in soil management systems. Eng. Agric. 34, 1162-1174.

Blanco-Canqui, H., Gantzer, C.J., Anderson, S.H., Alberts, E.E., 2004. Tillage and crop influences on physical properties for an Epiaqualf. Soil Sci. Soc. Am. J. 68, 567-

Blanco-Canqui, H., Lal, R., 2007. Regional assessment of soil compaction and structural properties under no-tillage farming. Soil Sci. Soc. Am. J. 71, 1770-1778.

Blanco-Canqui, H., Wienhold, B.J., Jin, V.L., Schmer, M.R., Kibet, L.C., 2017. Longterm tillage impact on soil hydraulic properties. Soil Tillage Res. 170, 38-42.

Bouma, J., Jongerius, A., Boersma, O.H., Jager, A., Schoonderbeek, D., 1977. The

Borges, J.A.R., Pires, L.F., Cássaro, F.A.M., Auler, A.C., Rosa, J.A., Heck, R.J., Roque, W.L., 2018. X-ray computed tomography for assessing the effect of tillage systems on topsoil morphological attributes. Soil Tillage Res. (submitted to publication). function of different types of macropores during saturated flow through four swelling soil horizons. Soil Sci. Soc. Am. J. 41, 945-950. 
583 Buczko, U., Bens, O., Huttl, R.F., 2006. Tillage effects on hydraulic properties and macroporosity in silty and sandy soils. Soil Sci. Soc. Am. J. 70, 1998-2007.

585

586

587

588

589

590

591

592

593

594

595

596

597

598

599

600

601

602

603

604

605

606

607

608

Bullock, P., Thomasson, A.J., 1979. Rothamsted studies of soil structure, II. Measurement and characterisation of macroporosity by image analysis and comparison with data from water retention measurements. J. Soil Sci. 30, 391413.

Bünemann, E.K., Bongiorno, G., Bai, Z., Creamer, R.E., De Deyn, G., de Goede, R., Fleskens, L., Geissen, V., Kuyper, T.W., Mäder, P., Pulleman, M., Sukkel, W., van Groenigen, J.W., Brussaard, L., 2018. Soil quality - A critical review. Soil Biol. Biochem. 120, 105-125.

Cameira, M.R., Fernando, R.M., Pereira, L.S., 2003. Soil macropore dynamics affected by tillage and irrigation for a silty loam alluvial soil in southern Portugal. Soil Tillage Res. 70, 131-140.

Carducci, C.E., Oliveira, G.C., Curi, N., Rossoni, D.F., Costa, A.L., Heck, R.J., 2014. Spatial variability of pores in Oxidic Latosol under a conservation management system with different gypsium doses. Ciênc. Agrotec. 38, 445-460.

Carducci, C.E., Zinn, Y.L., Rossoni, D.F., Heck, R.J., Oliveira, G.C., 2017. Visual analysis and X-ray computed tomography for assessing the spatial variability of soil structure in a cultivated Oxisol. Soil Tillage Res. 173, 15-23.

Cássaro, F.A.M., Borkowski, A.K., Pires, L.F., Rosa, J.A., Saab, S.C., 2011. Characterization of a Brazilian clayey soil submitted to conventional and no-tillage management practices using pore size distribution analysis. Soil Tillage Res. 111, 175-179.

Cavalieri, K.M.V., da Silva, A.P., Tormena, C.A., Leao, T.P., Dexter, A.R., Hakansson, I., 2009. Long-term effects of no-tillage on dynamic soil physical properties in a Rhodic Ferrasol in Paraná, Brazil. Soil Tillage Res. 103, 158-164. 
610

611

612

613

614

615

616

617

618

619

620

621

622

623

624

625

626

627

628

629

630

631

632

Costa, L.F., Antonino, A.C.D., Heck, R.J., Coutinho, A.P., Vasconcelos, T.C., Machado, C.B., 2018. X-ray computed microtomography in the evaluation of the porous system of soils. Rev. Bras. Eng. Agr. Amb. 22, 249-254.

Cunha, J.L.X.L., Coelho, M.E.H., Albuquerque, A.W., Silva, C.A., da Silva Junior, A.B., de Carvalho, I.D.E., 2015. Water infiltration rate in Yellow Latosol under different soil management systems. Rev. Bras. Eng. Agr. Amb. 19, 1021-1027.

da Silva, V.R., Reichert, J.M., Reinert, D.J., Bortoluzzi, E.C., 2009. Soil water dynamics related to the degree of compaction of two Brazilian oxisols under no-tillage. Rev. Bras. Ci. Solo 33, 1097-1104.

da Silva, F.R., Albuquerque, J.A., da Costa, A., Fontoura, S.M.V., Bayer, C., Warmling, M.I., 2016. Physical properties of a Hapludox after three decades under different soil management systems. Rev. Bras. Ci. Solo 40, e0140331.

Dal Ferro, N., Charrier, P., Morari, F., 2014. Soil macro- and microstructure as affected by different tillage systems and their effects on maize root growth. Soil Tillage Res. $140,55-65$.

Daraghmeh, O.A., Jensen, J.R., Petersen, C.T., 2008. Near-saturated hydraulic properties in the surface layer of a sandy loam soil under conventional and reduced tillage. Soil Sci. Soc. Am. J. 72, 1728-1737.

Daraghmeh, O.A., Jensen, J.R., Petersen, C.T., 2009. Soil structure stability under conventional and reduced tillage in a sandy loam. Geoderma 150, 64-71.

Doube, M., Kłosowski, M.M., Arganda-Carreras, I., Cordelières, F.P., Dougherty, R.P., Jackson, J.S., Schmid, B., Hutchinson, J.R., Shefelbine, S.J., 2010. Bone 47, 1076-1079. 
FEBRAPDP, 2013. Expansão da área cultivada em plantio direto. FEBRAPDP, Foz do Iguaçu, Brasil. (available at: https://febrapdp.org.br/area-de-pd). Accessed on November 2018.

Ferreira, T.R., Pires, L.F., Wildenschild, D., Heck, R.J., Antonino, A.C.D., 2018. X-ray microtomography analysis of lime application effects on soil porous system. Geoderma 324, 119-130.

Folegatti, M.V., Camponez do Brasil, R.P., Blanco, F.F., 2001. Sampling equipment for soil bulk density determination tested in a Kandiudalfic Eutrudox and a Typic Hapludox. Sci. Agri. 58, 833-838.

Franzluebbers, A.J., Stuedemann, J.A., Franklin, D.H., 2011. Water infiltration and surface-soil structural properties as influenced by animal traffic in the Southern Piedmond USA. Renew. Agric. Food Syst. 27, 256-265.

Fuentes, J.P., Flury, M., Bezdicek, D.F., 2004. Hydraulic properties in a silt loam soil under natural prairie, conventional till, and no-till. Soil Sci. Soc. Am. J. 68, 16791688.

Galdos, M.V., Pires, L.F., Cooper, H.V, Calonego, J.C, Rosolem, C.A. Mooney, S.J. 2018. Assessing the long-term effects of zero-tillage on the macroporosity of Brazilian soils using X-ray Computed Tomography. Geoderma 337, 1126-1135.

Garbout, A., Munkholm, L.J., Hansen, S.B., 2013. Tillage effect on topsoil structural quality assessed using X-ray CT soil cores and visual soil evaluation. Soil Tillage Res. 128, 104-109.

Gee, G.W., Or, D., 2002. Particle-size analysis. In: Dane, J.H., Topp, G.C. (eds.) Methods of Soil Analysis: Physical Methods. Soil Science Society of America Book Series, Madison, USA. pp. 255-293.

Hammer, Ø., Harper, D.A.T., Ryan, P.D. 2001. PAST: Paleontological statistics software package for education and data analysis. Palaeont. Elect. 4, 1-9. 
Helliwell, J.R., Sturrock, C.J., Grayling, K.M., Tracy, S.R., Flavel, R.J., Young, I.M., Whalley, W.R., Mooney, S.J., 2013. Applications of X-ray computed tomography for examining biophysical interactions and structural development in soil systems: a review. Eur. J. Soil Sci. 64, 279-297.

Hernández Zubeldia, E., Ozelim, L.C.S.M., Brasil Cavalcante, A.L., Crestana, S., 2016. Cellular automata and X-ray microcomputed tomography images for generating artificial porous media. Int. J. Geomech. 16, 04015057.

Hillel, D., 2004. Introduction to environmental soil physics. Elsevier Academic Press, San Diego.

Imhoff, S., Ghiberto, P.J., Grioni, A., Gay, J.P., 2010. Porosity characterization of Argiudolls under different management systems in the Argentine Flat Pampa. Geoderma 158, 268-274.

Jabro, J.D., Sainju, U.M., Stevens, W.B., Lenssen, A.W., Evans, R.G., 2009. Long-term tillage influences on soil physical properties under dryland conditions in northeastern Montana. Arch. Agron. Soil Sci. 55, 633-640.

Jarvis, N., Forkman, J., Koestel, J., Kätterer, T., Larsbo, M., Taylor, A., 2017. Longterm effects of grass-clover leys on the structure of a silt loam soil in a cold climate. Agr. Ecosyst. Environ. 247, 319-328.

Jefferies, D.A., Heck, R.J., Thevathasan, N. V., Gordon, A.M., 2014. Characterizing soil surface structure in a temperate tree-based intercropping system using X-ray computed tomography. Agrofor. Syst. 88, 645-656.

Katsvairo, T., Cox, W.J., van Es, H., 2002. Tillage and rotation effects on soil physical characteristics. Agron. J. 94, 299-304.

Katuwal, S., Norgaard, T., Moldrup, P., Lamandé, M., Wildenschild, D., de Jonge, L.W., 2015. Linking air and water transport in intact soils to macropore characteristics inferred from X-ray computed tomography. Geoderma 237/238, 9-20. 
Klein, V.A., Libardi, P.L., 2002. Densidade e distribuição do diametro dos poros de um latossolo vermelho, sob diferentes sistems de uso e manejo (Bulk density and pore size distribution of an Oxisol under different use and management systems). R. Bras. Ci. Solo 26, 857-867.

Lima, H.V. de, Lima, C.L.R. de, Leão, T.P., Cooper, M., Silva, A.P. da, Romero, R.E., 2005. Tráfego de máquinas agrícolas e alterações de bioporos em área sob pomar de laranja (Agricultural machinery traffic and alterations in biopores under an orange orchard). Rev. Bras. Ci. Solo 29, 677-684.

Mangalassery, S., Sjogersten, S., Sparkes, D.L., Sturrock, C.J., Craigon, J., Mooney, S.J., 2014. To what extent can zero tillage lead to a reduction in greenhouse gas emissions from temperate soils? Sci. Rep. 4, 4586.

Marchini, D.C., Ling, T.C., Alves, M.C., Crestana, S., Souto Filho, S.N., de Arruda, O.G., 2015. Matéria orgânica, infiltração e imagens tomográficas de Latossolo em recuperação sob diferentes tipos de manejo (Organic matter, water infiltration and tomographic images of Latosol in reclamation under different managements). Rev. Bras. Eng. Agr. Amb. 19, 574-580.

Martins, T., Saab, S.C., Milori, D., Brinatti, A.M., Rosa, J.A., Cassaro, F.A.M., Pires, L.F., 2011. Soil organic matter humification under different tillage managements evaluated by Laser Induced Fluorescence (LIF) and C/N ratio. Soil Tillage Res. $111,231-235$.

Mazurana, M., Levien, R., Inda Junior, A.V., Conte, O., Bressani, L.A., Muller, J., 2017. Soil susceptibility to compaction under use conditions in southern Brazil. Ci. Agrotec. 41, 60-71.

MINEROPAR, 2013. Serviço geológico do Paraná. Curitiba, Brasil. (available at: http://www.mineropar.pr.gov.br/modules/conteudo/conteudo.php?conteudo=154). Accessed on November 2018. 
711 Munkholm, L.J., Hansen, E.M., 2012. Catch crop biomass production, nitrogen uptake and root development under different tillage systems. Soil Use Managem. 28, 517529.

714

715

716

717

718

719

720

721

722

723

724

725

726

727

728

729

730

731

732

733

734

735

736

Munkholm, L.J., Heck, R.J., Deen, B., 2012. Soil pore characteristics assessed from Xray micro-CT derived images and correlations to soil friability. Geoderma 181/182, 22-29.

Muñoz-Ortega, F.J., San Jose Martinez, F., Caniego Monreal, F.J., 2015. Volume, surface, connectivity and size distribution of soil pore space in CT images: comparison of samples at different depths from nearby natural and tillage ares. Pre Appl. Geophys. 172, 167-179.

Nelson, D.W., Sommers, L.E., 1982. Total carbon, organic carbon, and organic matter. In: Page, A.L., Miller, R.H., Keeney, D.R. (eds.) Methods of Soil Analysis: Chemical and Microbiological Properties. American Society of Agronomy, Soil Science Society of America, Madison, USA. pp.539-580.

Odgaard, A., Gundersen, H.J.G., 1993. Quantification of connectivity in cancellous bone, with special emphasis on 3-D reconstructions. Bone 14, 173-182.

Ogunwole, J.O., Pires, L.F., Shehu, B.M. 2015. Changes in the structure of a Nigerian soil under different land management practices. Rev. Bras. Ci. Solo, 39, 830-840.

Otsu, N., 1979. A threshold selection method from gray-level histograms. IEEE Transactions on Systems, Man and Cybernetics I. SMC-9, 62-6.

Pagenkemper, S.K., Puschmann, D.U., Peth, S., Horn, R., 2014. Investigation of time dependent development of soil structure and formation of macropore networks as affected by various precrop species. Int. Soil Wat. Cons. Res. 2, 51-66.

Pagenkemper, S.K., Athmann, M., Uteau, D., Kautz, T., Peth, S., Horn, R., 2015. The effect of earthworm activity on soil bioporosity - Investigated with X-ray computed tomography and endoscopy. Soil Tillage Res. 146, 79-88. 
Pagliai, M., 1994. Micromorphology and soil management. In: Ringrose-Voase, A.J., Humphreys, G.S. (eds.) Soil Micromorphology: Studies in Management and Genesis. Developments in Soil Science 22, Elsevier, Amsterdam. pp. 623-640.

Pagliai, M., Vignozi, N., Pellegrini, S., 2004. Soil structure and the effect of management practices. Soil Tillage Res. 79, 131-143.

Passoni, S., Pires, L.F., Heck, R., Rosa, J.A., 2015. Three dimensional characterization of soil macroporosity by x-ray microtomography. Rev. Bras. Ciência do Solo 39, $448-457$.

Peña-Sancho, C., Lopez, M.V., Gracia, R., Moret-Fernandez, D., 2017. Effects of tillage on the soil water retention curve during a fallow period of a semiarid dryland. Soil Res. 55, 114-123.

Peth, S., Horn, R., Beckmann, F., Donath, T., Fischer, J., Smucker, A.J.M., 2008. Three-dimensional quantification of intra-aggregate pore-space features using synchrotron-radiation-based microtomography. Soil Sci. Soc. Am. J. 72, 897-907.

Pierret, A., Capowiez, Y., Belzunces, L., Moran, C.J., 2002. 3D reconstruction and quantification of macropores using X-ray computed tomography and image analysis. Geoderma 106, 247-271.

Pires, L.F., Borges, J.A.R., Rosa, J.A., Cooper, M., Heck, R., Passoni, S., Roque, W.L., 2017. Soil structure changes induced by tillage systems. Soil Tillage Res. 165, 6679.

Rasband, W., 2007. ImageJ.1997-2007. U.S. National Institutes of Health, Bethesda, MD, USA.

Reichert, J.M., Suzuki, L.E.A.S., Reinert, D.J., 2007. Compactação do solo em sistemas agropecuários e florestais: Identificação, efeitos, limites críticos e mitigação. Tópicos em Ciencia do Solo. pp. 49-134. 
Rezanezhad, F., Quinton, W.L., Price, J.S., Elliot, T.R., Elrick, D., Shook, K.R., 2010. Influence of pore size and geometry on peat unsaturated hydraulic conductivity computed from 3D computed tomography image analysis. Hydrol. Process. 24, 2983-2994.

Rogasik, H., Schrader, S., Onasch, I., Kiesel, J., Gerke, H.H., 2014. Micro-scale dry bulk density variation around earthworm (Lumbricus terrestris L.) burrows based on X-ray computed tomography. Geoderma 213, 471-477.

Roque, W.L., Souza, A.C.A. de, Barbieri, D.X., 2009. The Euler-Poincaré characteristic applied to identify low bone density from vertebral tomographic images. Rev. Bras. Reumatol. 49, 140-152.

Roque, W.L., Arcaro, K., Lanfredi, R.B., 2012. Trabecular network tortuosity and connectivity of distal radius from microtomographic images. Brazilian J. Biomed. Eng. 28, 116-123.

Rosetti, K.V., Centurion, J.F., de Souza Neto, E.L., 2013. Physical quality of an Oxisol afeter different periods of management systems. Rev. Bras. Ci. Solo 37, 15221534.

Sá, J.C.M., Séguy, L., Tivet, F., Lal, R., Bouzinac, S., Borszowskei, P.R., Briedis, C., dos Santos, J.B., Hartman, D.C., Bertoloni, C.G., Rosa, J., Friedrich, T., 2015. Carbon depletion by plowing and its restoration by no-till cropping systems in Oxisols of Subtropical and Tropical agro-ecoregions in Brazil. Land Degrad. Develop. 26, 531-543.

Soil Survey Staff, 2013. Simplified guide to soil taxonomy. USDA-Natural Resources Conservation Service, National Soil Survey Center, Lincoln, USA.

Soracco, C.G., Lozano, L.A., Balbuena, R., Ressia, J.M., Filgueira, R.R., 2012. Contribution of macroporosity to water flux of a soil under different tillage systems. Rev. Bras. Ci. Solo 36, 1149-1155. 
Soto-Gómez, D., Pérez-Rodríguez, P., Vázquez-Juiz, L., López-Periago, J.E., Paradelo, M., 2018. Linking pore network characteristics extracted from CT images to the transport of solute and colloid tracers in soils under different tillage managements. Soil Tillage Res. 177, 145-154.

Sterio, D.C., 1984. The unbiased estimation of number and sizes of arbitrary particles using the disector. J. Microsc. 134, 127-136.

Strudley, M.W., Green, T.R, Ascough, J.C. 2008. Tillage effects on soil hydraulic properties in space and time: State of the science. Soil Tillage Res. 99: 4-48.

Thurston, W.P., 1997. Three-dimensional Geometry and Topology, 1st ed. Princeton University Press, Princeton.

Toriwaki, J., Yonekura, T., 2002. Euler number and connectivity indexes of a three dimensional digital picture. Forma 17, 183-209.

Tseng, C.L, Alves, M.C., Crestana, S., 2018. Quantifying physical and structural soil properties using X-ray microtomography. Geoderma 318, 78-87.

Vaz, C.M.P., de Maria, I.C., Lasso, P.O., Tuller, M., 2011. Evaluation of an advanced benchtop micro-computed tomography system for quantifying porosities and poresize distributions of two Brazilian Oxisols. Soil Sci. Soc. Am. J. 75, 832-841.

Vogel, H.J., 1997. Morphological determination of pore connectivity as a function of pore size using serial sections. Eur. J. Soil Sci. 48, 365-377.

Vogel, H.J., Kretzschmar, A., 1996. Topological characterization of pore space in soil sample preparation and digital image-processing. Geoderma 73, 23-38.

Wang, J., Guo, L., Bai, Z., Yang, L., 2016. Using computed tomography (CT) images and multi-fractal theory to quantify the pore distribution of reconstructed soils during ecological restoration in opencast coal-mine. Ecol. Engineer. 92, 148-157. 
813 Yang, Y., Wu, J., Zhao, S., Han, Q., Pan, X., He, F., Chen, C., 2018. Assessment of 814 the responses of soil pore properties to combined soil structure amendments using $815 \quad$ X-ray computed tomography. Sci. Rep. 8, 695.

816 Zhao, D., Xu, M., Liu, G., Yao, X., Tuo, D., Zhang, R., Xiao, T., Peng, G., 2017. 817 Quantification of soil aggregate microstructure on abandoned cropland during 818 vegetative succession using synchrotron radiation-based micro-computed 819 tomography. Soil Tillage Res. 165, 239-246.

820 Zibilske, L.M., Bradford, J.M., 2007. Soil aggregation, aggregate carbon and nitrogen, 821 and moisture retention induced by conservation tillage. Soil Sci. Soc. Am. J. 71, $822 \quad 793-802$

823 Zingg, T., 1935. Beitrag zur Schotteranalyse. Schweiz. Mineral. Petrogr. Mitt., 15, 39824140.

825

826

827 


\section{Figure Captions}

Fig. 1. $3 D$ reconstruction of selected soil cores $(\approx 5.0 \mathrm{~cm}$ high and $\approx 4.8 \mathrm{~cm}$ inner diameter) and pore spaces for the different management systems studied. The soil sample images were reconstructed with a resolution of $35 \mu \mathrm{m}$.

Fig. 2. Morphological properties of the soil porous system of a Brazilian Rhodic Hapludox submitted to different management systems (F: secondary forest; ZT: zerotillage; CT: conventional tillage; RT: reduced tillage). (a) Porosity (P). (b) Number of pores (NP). (c) Degree of anisotropy (DA). (d) Volumetric Euler-Poincare Characteristic $\left(E P C_{V}\right) .(e)$ Euler Number (EN) of the largest pore.

Fig. 3. Tortuosity of the soil porous system of a Brazilian Rhodic Hapludox submitted to different management systems (F: secondary forest; ZT: zero-tillage; CT: conventional tillage; RT: reduced tillage). (a) Average tortuosity $(\tau)$. (b) Tortuosity in the $x$ direction $\left(\tau_{x}\right)$. (c) Tortuosity in the y direction $\left(\tau_{y}\right)$. (d) Tortuosity in the $z$ direction $\left(\tau_{z}\right)$.

Fig. 4. Contribution of the different pore shapes to porosity for the Brazilian Rhodic Hapludox submitted to different management systems (F: secondary forest; ZT: zerotillage; CT: conventional tillage; RT: reduced tillage). (a) Pores of equant (EQ) shape. (b) Pores of prolate (PR) shape. (c) Pores of oblate (OB) shape. (d) Pores of triaxial (TR) shape.

Fig. 5. Contribution of different sizes of pores to the volume of pores (VP) for the Brazilian Rhodic Hapludox submitted to different management systems (F: secondary 
forest; ZT: zero-tillage; CT: conventional tillage; RT: reduced tillage). (a) Volume of pores between 0.0004 to $0.01 \mathrm{~mm}^{3}$. (b) Volume of pores between 0.01 to $0.1 \mathrm{~mm}^{3}$. (c) Volume of pores between 0.1 to $10 \mathrm{~mm}^{3}$. (d) Volume of pores $>10 \mathrm{~mm}^{3}$. 
Table 1. Texture (clay, silt, sand), macroporosity (Ma), microporosity (Mi) and organic carbon (OC) for the experimental areas under zero-tillage (ZT), conventional tillage $(C T)$, reduced tillage $(R T)$ and secondary forest $(F)$ studied.

\begin{tabular}{ccccccc}
\hline $\begin{array}{c}\text { Property/ } \\
\text { System }\end{array}$ & Clay & Silt & Sand & Ma & Mi & OC \\
\cline { 2 - 7 } & & $\left(\mathbf{g ~ k g}^{-1}\right)$ & & $\left(\mathbf{c m}^{\mathbf{3}} \mathbf{c m}^{-3}\right)$ & $\left.\mathbf{( g ~ k g}^{-1}\right)$ \\
\hline ZT & 530 & 300 & 170 & 0.10 & 0.43 & 55.8 \\
CT & 610 & 220 & 170 & 0.19 & 0.37 & 31.7 \\
RT & 580 & 260 & 160 & 0.15 & 0.39 & 41.0 \\
F & 590 & 340 & 70 & 0.14 & 0.38 & 80.7 \\
\hline
\end{tabular}

Ma: macroporosity; Mi: microporosity; OC: organic carbon. Mi was determined in undisturbed samples submitted at $-6 \mathrm{kPa}$ in an Eijkelkamp® suction table. The $\mathrm{OC}$ of the secondary forest was extracted from the work of Sá et al. (2015) for the surface layer $(0-10 \mathrm{~cm})$.

Table 2. Culture rotations per year for the experimental areas under zero-tillage (ZT), conventional tillage (CT) and reduced tillage (RT) studied.

\begin{tabular}{|c|c|c|}
\hline \multirow[t]{2}{*}{ Year } & \multicolumn{2}{|c|}{ Management system and crop sequence } \\
\hline & CT and $R T$ & ZT \\
\hline $1981-1990$ & W/S & $\begin{array}{c}\mathrm{C} / \mathrm{O} / \mathrm{S}-\mathrm{W} / \mathrm{S} / \mathrm{L}-\mathrm{C} / \mathrm{O} / \mathrm{S}-\mathrm{W} / \mathrm{S} / \mathrm{L}- \\
\mathrm{C} / \mathrm{O} / \mathrm{S}-\mathrm{W} / \mathrm{S}\end{array}$ \\
\hline 1990-1995 & O/S - O/C - W/S - O/S - L/C & Similar to CT and RT \\
\hline 1995-2000 & $\mathrm{O} / \mathrm{S}-\mathrm{W} / \mathrm{S}-\mathrm{O}+\mathrm{V} / \mathrm{C}-\mathrm{O} / \mathrm{S}-\mathrm{W} / \mathrm{C}$ & Similar to CT and RT \\
\hline 2000-2009 & $\begin{array}{c}\mathrm{O} / \mathrm{S}-\mathrm{O} / \mathrm{C}-\mathrm{W} / \mathrm{S}-\mathrm{O}+\mathrm{V} / \mathrm{S}-\mathrm{O} / \mathrm{C}- \\
\mathrm{O} / \mathrm{S}-\mathrm{O} / \mathrm{C}-\mathrm{O} / \mathrm{S}-\mathrm{O} / \mathrm{C}-\mathrm{V} / \mathrm{S}\end{array}$ & Similar to CT and RT \\
\hline 2009-2017 & $\mathrm{O} / \mathrm{C}$ & Similar to CT and RT \\
\hline
\end{tabular}

Table 3. Indices utilized for the classification of pores in terms of shape.

\begin{tabular}{ccccc}
\hline Axes ratio & \multicolumn{4}{c}{ Shape } \\
& Equant (EQ) & Prolate (PR) & Oblate (OB) & Triaxial (TR) \\
\cline { 2 - 5 } Int./Maj. & $\geq 2 / 3$ & $<2 / 3$ & $\geq 2 / 3$ & $<2 / 3$ \\
Min./Int. & $\geq 2 / 3$ & $\geq 2 / 3$ & $<2 / 3$ & $<2 / 3$ \\
\hline
\end{tabular}

Int.: intermediate axis; Maj.: major axis; Min.: minor axis 
FOREST (F)

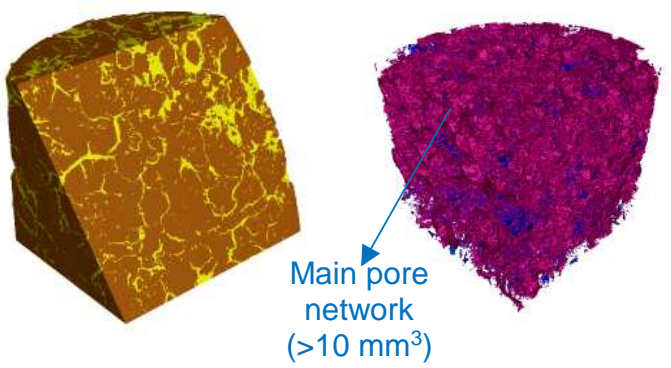

CONVENTIONAL TILLAGE (CT)

of pores at the sample surface ${ }^{k}$

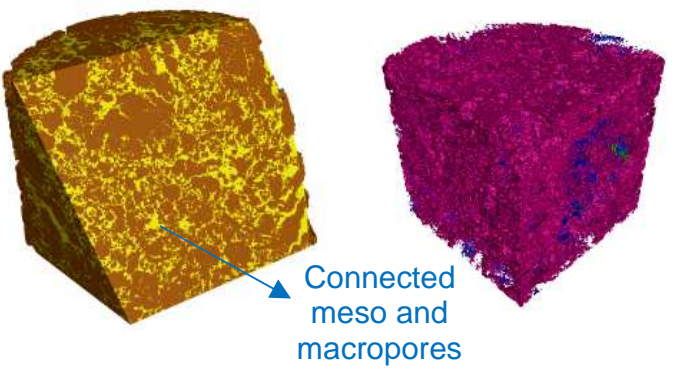

ZERO-TILLAGE (ZT)

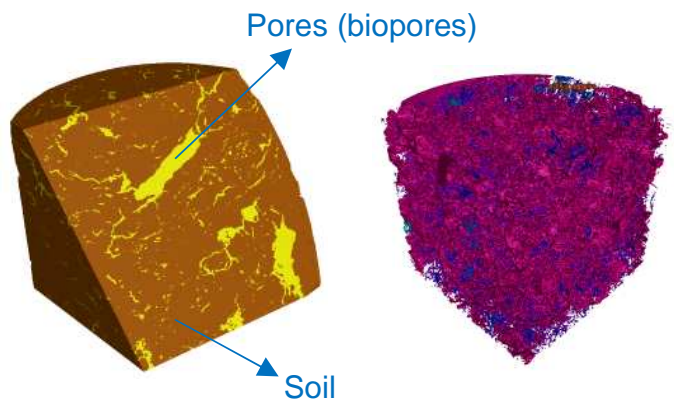

REDUCED TILLAGE (RT)
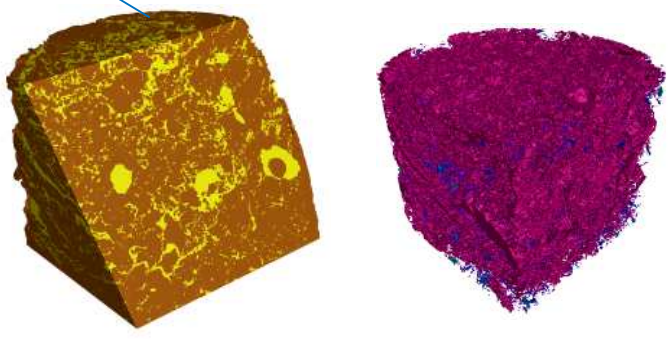

Fig. 1. 3D reconstruction of selected soil cores $(5.0 \mathrm{~cm}$ high and $4.8 \mathrm{~cm}$ inner diameter) and pore spaces for the different management systems studied. The soil sample images were reconstructed with a resolution of $35 \mu \mathrm{m}$. 


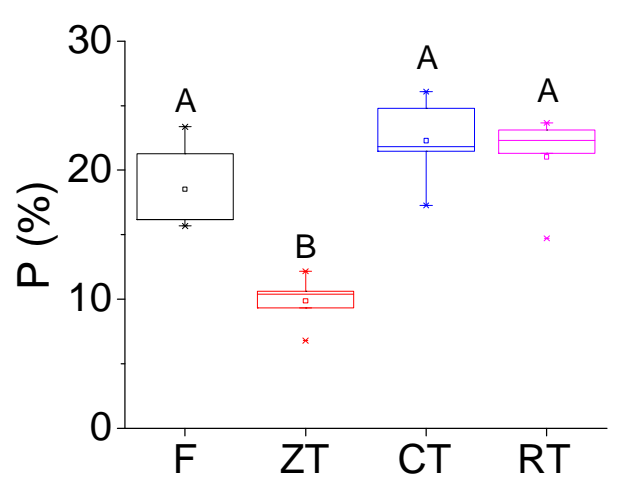

(a)

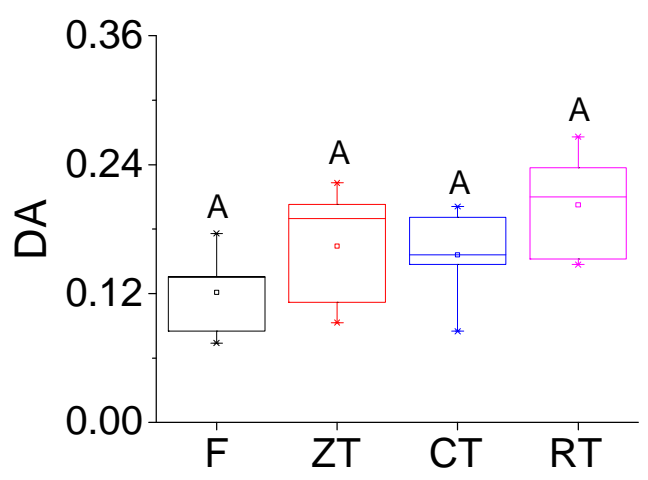

(c)

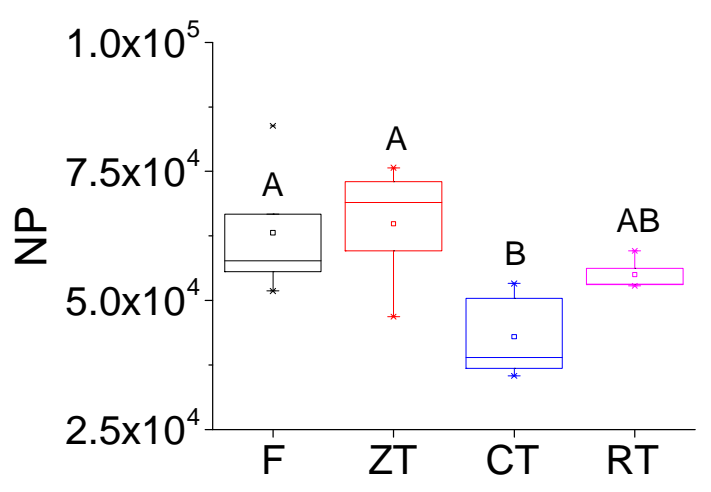

(b)

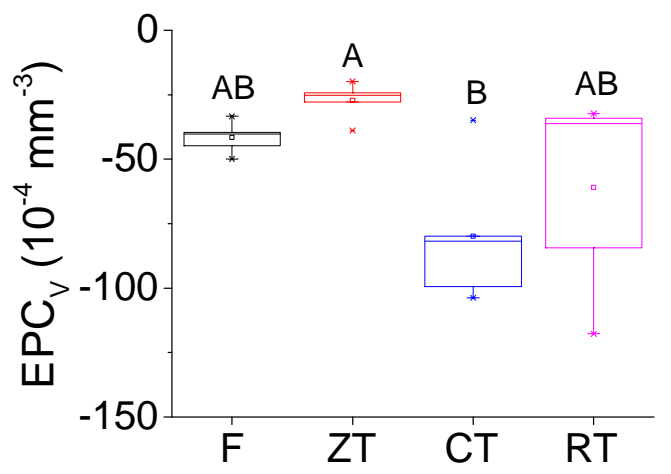

(d)

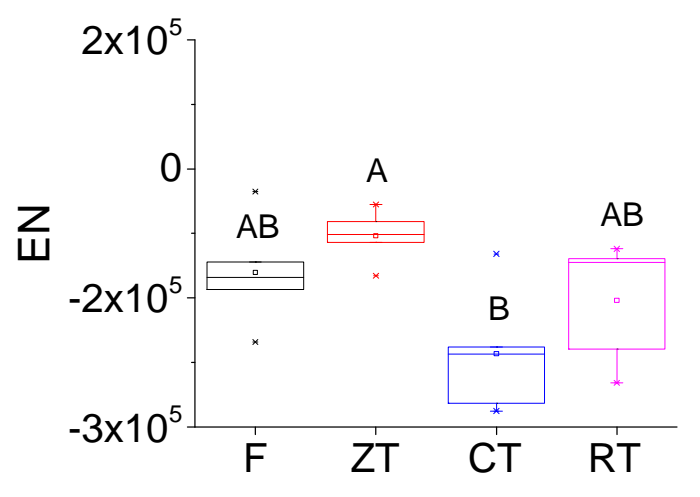

(e)

Fig. 2. Morphological properties of the soil porous system of a Brazilian Rhodic Hapludox submitted to different management systems (F: secondary forest; ZT: zerotillage; CT: conventional tillage; RT: reduced tillage). (a) Porosity (P). (b) Number of pores (NP). (c) Degree of anisotropy (DA). (d) Volumetric Euler-Poincare characteristic $\left(E P C_{V}\right)$. (e) Euler Number (EN) of the largest pore. 


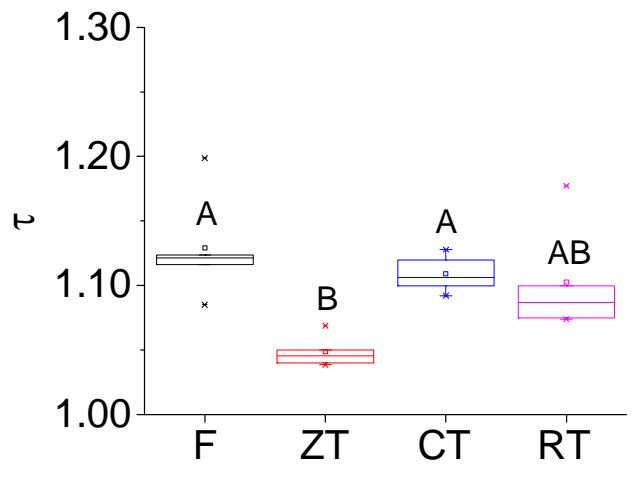

(a)

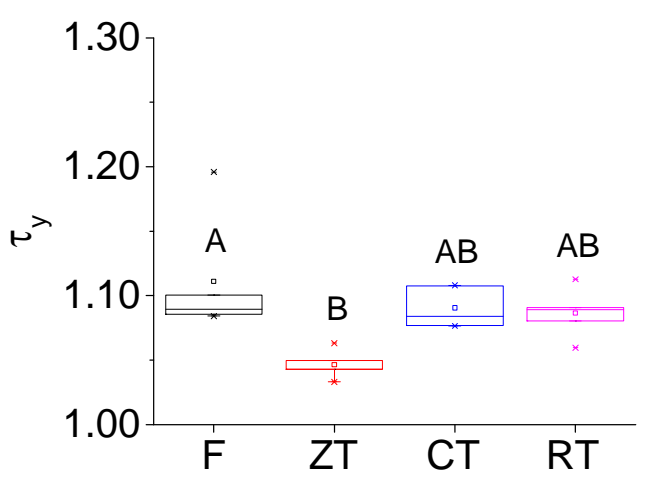

(c)

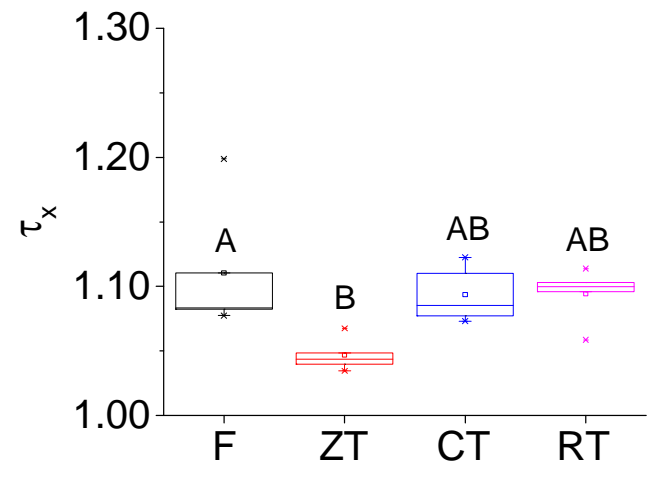

(b)

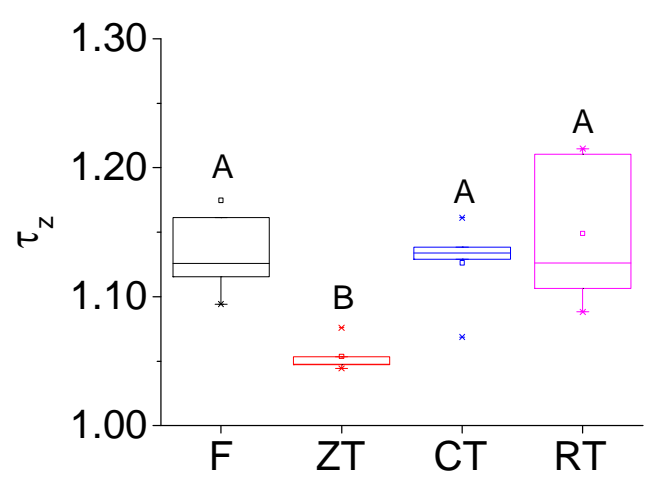

(d)

Fig. 3. Tortuosity of the soil porous system of a Brazilian Rhodic Hapludox submitted to different management systems (F: secondary forest; ZT: zero-tillage; CT: conventional tillage; RT: reduced tillage). (a) Average tortuosity $(\tau)$. (b) Tortuosity in the $x$ direction $\left(\tau_{x}\right)$. (c) Tortuosity in the $y$ direction $\left(\tau_{y}\right)$. (d) Tortuosity in the $z$ direction $\left(\tau_{z}\right)$. 


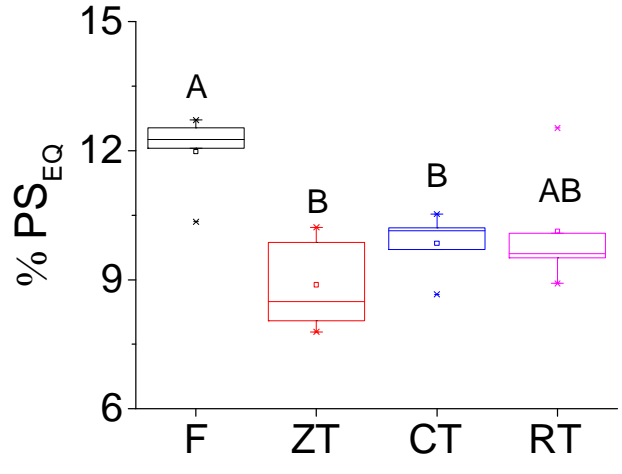

(a)

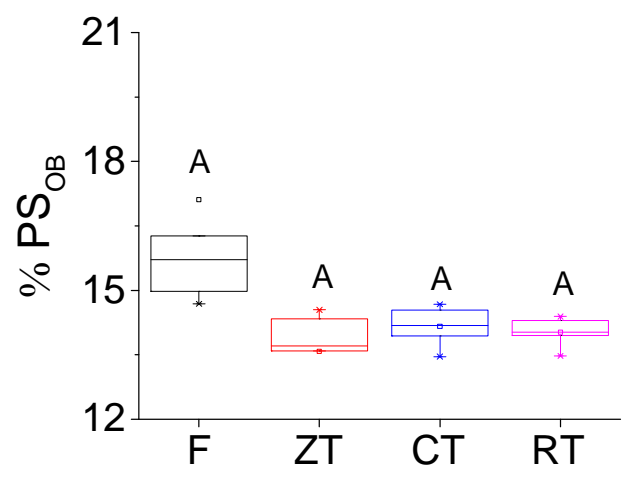

(c)

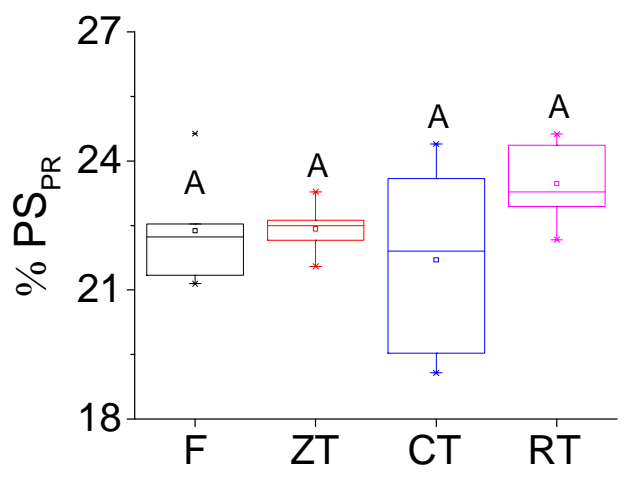

(b)

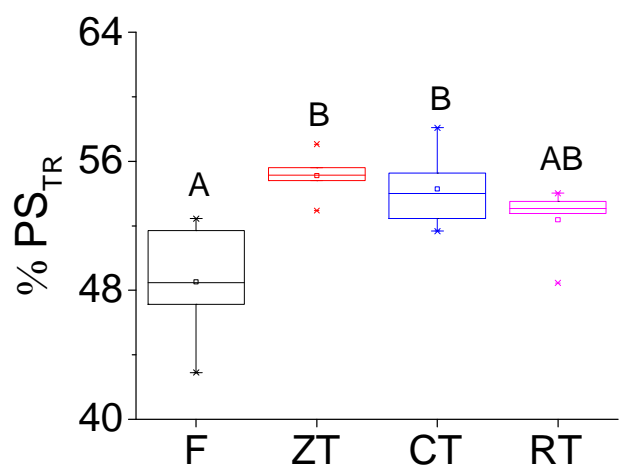

(d)

Fig. 4. Contribution of the different pore shapes to porosity for the Brazilian Rhodic Hapludox submitted to different management systems (F: secondary forest; ZT: zerotillage; CT: conventional tillage; RT: reduced tillage). (a) Pores of equant (EQ) shape. (b) Pores of prolate (PR) shape. (c) Pores of oblate (OB) shape. (d) Pores of triaxial (TR) shape. 


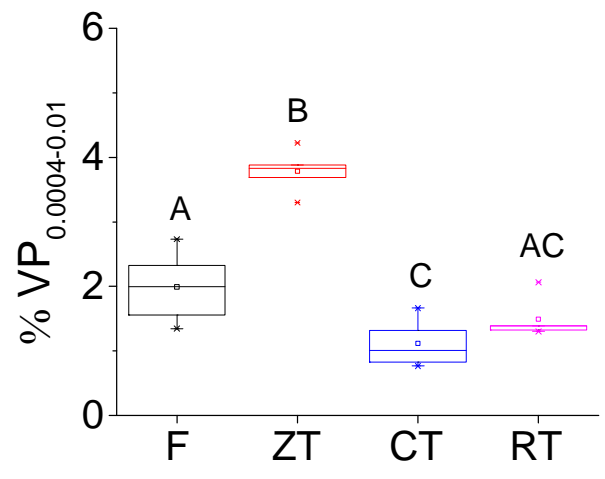

(a)

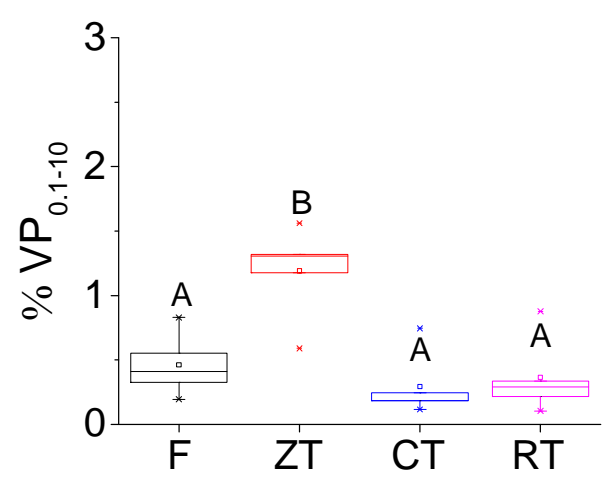

(c)

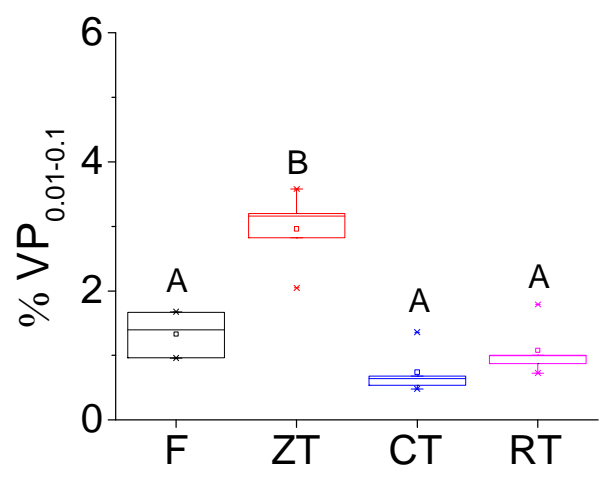

(b)

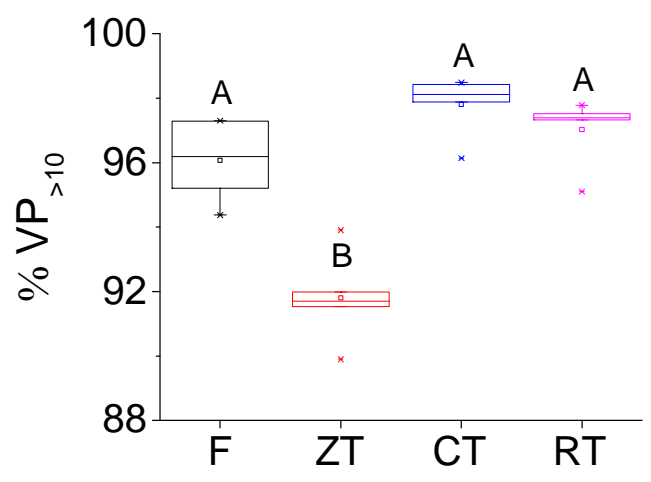

(d)

Fig. 5. Contribution of different sizes of pores to the volume of pores (VP) for the Brazilian Rhodic Hapludox submitted to different management systems (F: secondary forest; ZT: zero-tillage; CT: conventional tillage; RT: reduced tillage). (a) Volume of pores between 0.0004 to $0.01 \mathrm{~mm}^{3}$. (b) Volume of pores between 0.01 to $0.1 \mathrm{~mm}^{3}$. (c) Volume of pores between 0.1 to $10 \mathrm{~mm}^{3}$. (d) Volume of pores $>10 \mathrm{~mm}^{3}$. 